\title{
Countermeasures and Effects of the Big Data Marketing on the Business Operational Management
}

\author{
Zhihong $\mathrm{Li}^{1, *}$ \\ ${ }^{1}$ Business School, Jiang Han University, Wuhan, Hubei 430056, China \\ *Corresponding author. Email: linanwudingbang@163.com
}

\begin{abstract}
The popularization and application of the big data technology has been greatly changing the people's life and the business activities. The digitization of the consumption market is driving the enterprise to adjust all its operational sections. The big data marketing is a revolutionary change. It is also reforming the other sections of the business. How does it affect the other operational activities and what measures should be adopted? To answer these questions, the paper first explores the relationship between the big data marketing and the other business operational management, then analyzes the influence of the big data marketing to the other business activities such as that the establishment, implementation and change of the business strategic aim must be based on the precise information from the big data marketing and so forth, finally puts forward some tactics like the application of the big data technology in the business operation, digital of the marketing section, etc. since the big data have been penetrating the whole society either in the industry or in people's life or in the various marketplaces.
\end{abstract}

Keywords: countermeasures, effects, big data marketing, business operational management

\section{INTRODUCTION}

With the wide use in the economic society, the big data have been leaving more and more influence on the business world. The enterprise, whether big or small, is obliged to change itself to adapt the new market environment. On the one hand, it must innovate its operational sections like marketing, production, design and supply, etc; on the other hand, it must base its innovation on the market demand by making full use of the big data. In this process, the big data marketing plays a key role among the various operational parts of the business. What effects of the big data marketing are left on the other business parts and how the enterprise should take the steps to deal with the effects are worthwhile to be further discussed.

\section{RELATIONSHIP BETWEEN THE}

\section{MARKETING ON THE BIG DATA AND THE}

\section{OPERATIONAL MANAGEMENT OF THE BUSINESS}

The operational management of the business means the process that the managers at all the levels of the enterprise make its value chain value-added by planning, organizing, commanding, coordinating and controlling, etc. so as to realize its strategic target. It concerns series of activities like market investigation, product design, production, logistics and marketing and so on. It consists of the management in personnel, quality, cost, equipment and funds, etc. (see "Fig. 1")

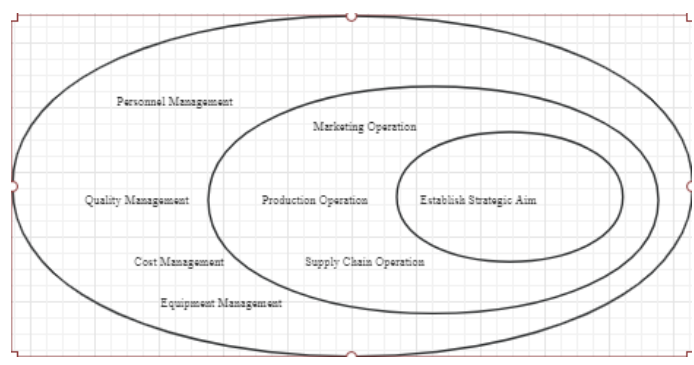

Fig. 1. General Operational System of the Business.

The big data marketing is aimed at helping the enterprise locate the target consumer by collecting massive data concerning the consumer on the internet so that the enterprise could adopt the precise marketing countermeasures such as in product design, pricing, place and ads. It has a close relationship with the business operation. First, the establishment of the business strategic aim must be based on the marketing investigation through the big data. Only in this way can the enterprise get the exact outcome about the consumer's conduct feature like preference and purchasing habit and make decisions of what, how much it will produce and whom it will serve. Then, the big data marketing is the key section of the business operation. With its precise marketing information, the enterprise can fully understand the demand and expectation of the latent consumer and make an exact position in the market. This will provide supports for the market forecast and decision and do benefits to the 
customer relationship management by stage. The precise marketing operation can make the production and the supply chain operations in order and resources saving. Next, the big data marketing does good to the supervision of the marketing rival. The product development, price and consumer resources, etc. are confidential to the rival. The enterprise may get some information about them by the big data analysis such as brand spreading, product performance and user interaction and so forth so as to support the brand crisis management [1]. Naturally, the business operational management makes the big data marketing have a clear objective. This is helpful to raising the value of the big data marketing activities. The enterprise can base its analysis of the big data marketing on its current productive activities. In all, the big data marketing and the operational management of the business are closely connected, interact and constrain each other.

\section{INFLUENCE ON THE OPERATION OF THE BUSINESS FROM THE MARKETING OF THE BIG DATA}

The influence from the big data marketing on the operation of the business is mainly reflected both inside and outside the enterprise. From inside the enterprise, the big data marketing guides the establishment of the strategic aim, the personnel management and arrangement of the resources. First, the establishment of the strategic aim must be based on the information got from the big data marketing in the consumer, rival, supplier and industrial regulations, etc. Then, once the strategic aim has been set up, the allocation of the resources in the enterprise such as funds, technology, buildings and people needs the support of the big data, particularly the arrangement of the human resources. The influence on the funds is mainly embodied in such aspects as the variety of the accountant information like structural and non-structural data, the various monetary measuring units like yuan, time or quantity, the expansion of the financial statement and so forth. Under the big data marketing, besides the professional technology and common management knowledge, some other technologies are obliged. Take it for example, the statistic knowledge, the math skill and the IT technology. However, To some degree, the people are the most important resources. In the enterprise, the employee is the customer, too. The enterprise should set up the personnel data bank so as to make a dynamic management to its people in their demand, growth and flow and to formulate a planning to develop their potential ability. In the current situation, any enterprise can't keep away from the innovation. The potential ability of the people is the endless source of the innovation, which is the core competitive competence of the enterprise. The big data marketing in the human resource market can provide more precise information for the dynamic personnel management of the enterprise and strengthen its validity [2].

From outside the enterprise, the big data marketing serve the enterprise either in the customer or in the supplier or in the rival. First, based on the big data marketing analysis, more precise and timely information about the customer or consumer can be found out so that the enterprise would segment the market and offer the correspondent personified items or service by way of analyzing, identifying and forecasting the individual demand [3]. At the same time, with the big data technology fast evolving, the marketing activities are changing from the traditional mass marketing to the precise marketing. The precise marketing technology is able to help the enterprise dig out the preference of the hidden customer's demand and provide the needed item so as to satisfy the customer or to stimulate the customer's want. What's more, the immense value brought to the business by the big data marketing lies in the fact as following: because the people's life is widely digitized, the enterprise can gather more information than ever before about the customer's behavior, habit, way of life, interests and social communication, etc. by internet. All this information is much helpful to the decision making of the various section of the operational management like real marketing and so on. Second, the big data marketing is making the precise marketing or real marketing a trend. This trend may greatly change the production and supply process. The production on time or just in time or customized is sure to reform the supply section. The supply on the line may be much needed. The timely, exact and real marketing information is quite important to the supplier. In this way, the big data marketing can cut down not only the marketing cost but also the price of the physical distribution of the enterprise. Third, the big data marketing does good to the supervision of the rival and the communication of the brand. Generally speaking, any enterprise should understand what its rival is doing. But who is willing to show your business secret to your competitor? The enterprise may get it by analyzing the information from the big data marketing. In the meanwhile, the brand communication such as brand trend, brand feature, user preference and word of mouth of the item, etc. can be effectively located through the big data marketing [4]. Besides, the big data marketing can provide the support for the brand risk management. In the times of the new mass media, it's a rule for the consumer's demand to change fast. Any brand is always facing risks to be replaced. The enterprise may spot the crisis beforehand with the help of the big data marketing, follow the orientation of the risk, identify the key element and deal with it quickly. 


\section{TACTICS OF THE OPERATION FOR THE BUSINESS BASED ON THE MARKETING OF THE BIG DATA}

The operation of the business consists of such functions as marketing, production, technology, finance and personnel, etc. In the current global market, the marketing is both the start point and the final [5]. Due to the wide use of the information and internet technology, the big data is vital to the marketing today. The big data marketing has left much influence on the operation of the business. To some degree, in the fierce competitive market, the big data marketing determines whether the business operation succeeds or fails. In the background of the big data marketing, the enterprise should adjust its operational tactics in the following aspects.

\section{A. Application of the big data technology in the business operation}

The big data technology refers to the integration of such information technology as internet, internet of things, cloud computation and artificial intelligence, etc. It can fast acquire the valuable information from the various data. It is the frontier of the digital analysis. It is now changing the people's life and work style, the business operational process and even the scientific research model [6]. In the course of the business operation, the big data technology can help the enterprise make a precise judgement of the information from various operational sections like customers, production, finance, personnel and suppliers, etc. so that the enterprise can adopt the effective operational style [7]. By way of using the big data technology, the enterprise can gather, analyze and deal with the information in time both from inside and outside and dynamically make its operational decisions [8].

\section{B. Digitalizing the marketing section}

The big data do many benefits to the business marketing. First, the enterprise can collect the needed real information fast at a lower cost and easily follow the consumer's behavior change by internet and adjust its marketing measures in time. Then, with the big data technology, the marketer can identify the individual's preference and trace his or her conduct and purchasing experience. Next, the designer of the enterprise can design what the consumer wants according to the above information. So, the enterprise must strengthen the construction of the big data system and digitize all the parts of the marketing section so as to fully use the big data technology to serve its operation.

\section{Fully integrating the inner information and combine the information management system with the inner control institutions}

Under the background of the big data, many nonstructural data always affect the traditional structural financial data. It is worthwhile for the enterprise to explore the non-structural data management system so as to transform them into the valuable information available to be used. To reach this target, the enterprise ought to highly integrate the information in customers, business, strategy and operation and make its accountancy change from the accounting model to the value-added type [9]. At the same time, the enterprise should set up a security appraisal mechanism of the accounting information adaptive to its business development so as to regularly supervise the security of the inner accounting information [10].

\section{Reinforcing the personnel training in applying the big data technology in order to make a better use of the information from the big data marketing}

In the conditions of the big data, the administrative department should fully recognize the importance of the big data marketing to the business operation and set up the platform to use data by inputting sufficient finance, materials and personnel. The correspondent training ought to be offered to both the manager and the common people. The training focus not only on how to find out the valuable information through analyzing the business operational problems and solving them, but also on all the people's sense of data to support their decision. To realize this target, the enterprise should be prepared for this work. First, formulate the valid plan of the human resources management based on the business strategic aim. This plan is the guide to develop the needed people both inside and outside the enterprise. Then, renew the recruitment process based on the big data. Under the big data, the enterprise can get the candidate's information from various paths besides the traditional paper personnel resume like via social network and interview, etc. In this way, the employer can more clearly understand the candidate and well match him or her with the position. Next, specifically train the personnel. In the times of the big data, it's necessary for the enterprise to popularize the big data knowledge among all its people. Moreover, it should hire or train the skilled personnel in the big data technology so that they can familiarly collect, analyze and deal with the massive data to get the useful message. In the meanwhile, set up the correspondent personnel evaluation system based on the big data technology. This kind of the system should be able to help the manager find out the latent relationship among the information and improve its drawbacks so as to strengthen the effectiveness of the personnel assessment After all, whether they are in the marketing department 
or in the other departments in an enterprise, people play much more importance than the other resources.

\section{CONClusion}

The big data marketing is the product of the science and technology. As an important part of the business operation, it is leaving much more effects on the other parts of the business operation than ever before. The enterprise must well coordinate them so that they can run smoothly as a whole organic system. Various resources like people, materials and finance, etc. form this system. However, the people play a decisive role in it. Therefore, to successfully deploy the business operational activities, the enterprise should develop the needed people able to match the evolution of the big data technology.

\section{Acknowledgment}

The paper is funded by the Discipline Group of the Integrative Management Between Economy and Industry in the City Circle, by the Wuhan Studies Institute, Hubei, China (IWHS20172001), and by Research Center on the Development of the Manufacturing Industry of the Wuhan City Circle, China (wz201607).

\section{References}

[1] https://baike.baidu.com/item/\%E5\%A4\%A7\%E6\%95\%B0\%E6 $\% 8 \mathrm{D} \%$ AE\% $\%$ E\%90\%A5\%E9\%94\%80/1182844?fr=aladdin.

[2] Fen Zhu. Research of the Innovation for the Marketing Strategy of the Enterprise in the New Situation. No.21, 2018.

[3] Lishan Chen. Internet+Big Data and Marketing Innovation, Communication Business Management. No.6, 2015, pp18-19.

[4] https://www.sohu.com/a/222430232_240534.

[5] Zhaoyang Chen. Development and Analysis of the Marketing Strategy in the Enterprise Under the Big Data. Public Relation World. No.13, 2019.

[6] http://www.qianjia.com/zhike/html/2019-07/9_7359.html.

[7] Xiaofang Kang. Study on the Marketing Model Innovation Based on the Internet+, Modern Marketing(late monthly). No.6,2017.

[8] Yajuan Jing. Challenges and Tactics of the Operational Management in the Enterprise in the Times of the Big Data, Scientific \& Technological Outlook. No.28, 2016.

[9] Zhenxing Yuan, Qingna Zhang, Xiaolin Zhang, Xiaoxue Zhang. Challenge of the Big Data to the Accounting and Tactics. Friend to Accounting, No.32, 2014, pp89-92.

[10] Weikeng Lian. Influence of the Big Data Is on the Operational Model of the Modern Enterprise. http://www.doc88.com/p1126632794068.html, 2015-11-26 19:12:58. 